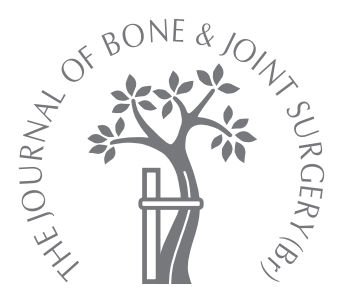

Y. Falkinstein, E. R. Ahlmann, L. R. Menendez

From University of Southern California, California, USA

\section{Reconstruction of type II pelvic resection with a new peri-acetabular reconstruction endoprosthesis}

Y. Falkinstein, MD Orthopaedic Surgeon E. R. Ahlmann, MD, Assistant Professor of Orthopaedic Surgery Department of Orthopaedic Surgery

Los Angeles County-University of Southern California Medical Center, 1200 N. State Street, GNH 3900, Los Angeles, California 90033, USA.

" L. R. Menendez, MD, FRCS, Professor of Orthopaedic Surgery

University of Southern California University Hospital, 1510 San Pablo Street, Suite 634, Los Angeles, California 90033, USA.

Correspondence should be sent to Professor E. R. AhImann: e-mail:

ahlmann2002@yahoo.com

C2008 British Editorial Society of Bone and Joint Surgery doi:10.1302/0301-620X.90B3. $20144 \$ 2.00$

$J$ Bone Joint Surg $[\mathrm{Br}]$ 2008;90-B:371-6.

Received 24 August 2007;

Accepted 15 November 2007

We report our early experience with a new peri-acetabular reconstruction endoprosthesis used for pelvic reconstruction after tumour resection. The outcome of 21 patients who underwent limb salvage following type II pelvic resection and reconstruction using the periacetabular reconstruction prosthesis between 2000 and 2006 was retrospectively reviewed. This prosthesis was designed to use the remaining part of the ilium to support a horizontally placed acetabular component secured with internal fixation and bone cement. Into this device a constrained acetabular liner is positioned which is articulates with a conventional femoral component to which a modular extension and modular head are attached. The mean follow-up was $\mathbf{2 0 . 5}$ months (1 to 77). The most common complications were deep infection, superficial wound infections, and dislocation. The mean musculoskeletal tumor society functional outcome score for the survivors was 20.1(11 to 27).

We recommend the use of the peri-acetabular reconstruction prosthesis for reconstruction of large defects after type II pelvic resection, as this design has a greater inherent stability over other available prostheses.

Most bone tumours involving the pelvis are metastases usually from tumours of the lung, prostate or breast. ${ }^{1}$ Only $5 \%$ of primary malignant bone tumours involve the pelvic girdle, ${ }^{1}$ which in skeletally-mature patients is most commonly a chondrosarcoma. Other locally destructive benign tumours such as giant cell tumours can involve the pelvis.

Reconstruction after resection of neoplasms involving the acetabulum remains one of the most demanding procedures. Preservation of the limb without retaining reasonable function is unsatisfactory.

The location of tumours in the pelvis and the requirement for en bloc resection has been classified into three types. ${ }^{2}$ A type I procedureinvolves resection of the ilium, type II resection of the acetabulum, and type III resection of the ischium and pubic rami. Type II procedures pose the greatest reconstructive challenge because of the resection a functional hip joint. Many techniques have been used to preserve some function of the hip. The simplest method is to leave the limb flail and allow a pseudarthrosis to form which permits movement. The hip is, however, unstable and frequently painful. Some have advocated attempting to arthrodese the femur to the remaining pelvis. $^{3-5}$ However, is chiofemoral or iliofemoral arthrodeses have a low success rate, and even if suc- cessful often results in a substantial limb length discrepancy and difficulty with sitting and walking. The use of bulk allografts can result in a good outcome but complications such as allograft fracture and infection can be devastating. ${ }^{6-8}$

Recent studies ${ }^{9-15}$ have focused on the use of prosthetic components in the reconstruction of the hip. While standard femoral components can be used, acetabular reconstruction has required custom made components ${ }^{9}$ or the Mark II saddle prosthesis (Link Orthopaedics, Rockaway, New Jersey). ${ }^{10-15}$ A custom acetabular prosthesis based on CT reconstructions and computer-aided design, can provide intimate fixation to bone. This eliminates micromovement between the bone and the implant and minimises bony erosion and pain. ${ }^{9}$ However, achieving this exact fit requires timeconsuming sculpting of the bone at operation and if the amount of resection required exceeds that allowed by the custom implant, adaptation is not readily feasible.

The saddle prosthesis was originally designed for salvage of massive acetabular defects in revision hip replacement. ${ }^{10-15}$ It has since been modified and adapted for oncological applications. The saddle portion of the implant is not intimately secured to bone but articulates in a bony window made in the 


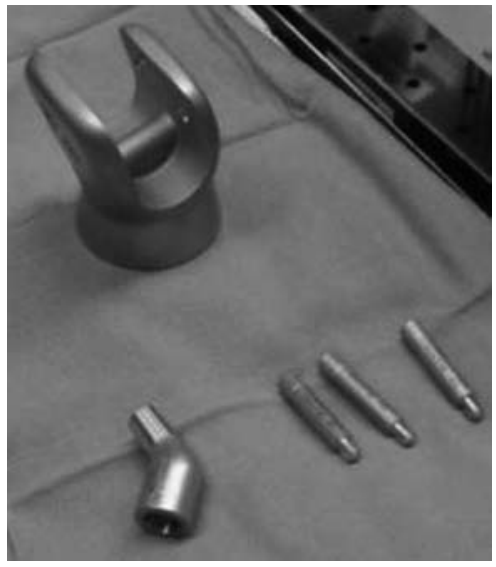

Fig. 1a

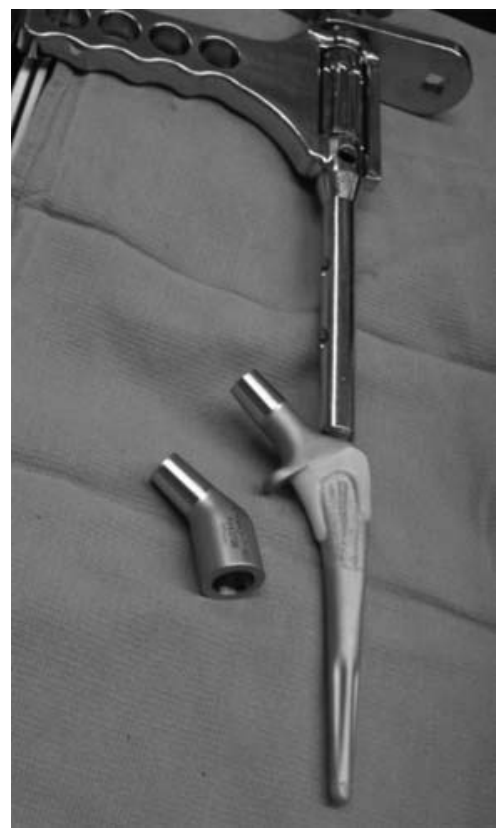

Fig. 1b

a) Photograph showing the peri-acetabular replacement prosthesis from above with the two wing plates joining into a bell. The gap between the wings into which the remaining ilium is placed can be seen. The three cross locking bolts are seen at the bottom right of the photograph. b) A photograph of the femoral component with the femoral neck extension on the left. The introducer is attached to the femoral component.

remaining ilium. This window must be sufficiently wide and deep to accommodate the width of the saddle to provide general anteroposterior (AP) stability. However, the movement at the bone-prosthesis interface may result in bony erosion and pain. The prosthesis has also been reported to dislocate from the bony window. ${ }^{11-13}$
A peri-acetabular replacement prosthesis (StrykerHowmedica, Rutherford, New Jersey) provides greater surgical freedom and secure fixation of the implant to bone. We report our early experience with this new endoprosthesis.

\section{Patients and Methods}

We retrospectively reviewed our orthopaedic oncology database and identified 21 patients who had undergone limb salvage with pelvic resection and acetabular reconstruction using the peri-acetabular replacement prosthesis between 2000 and 2006. Of these, 13 had metastatic tumours and eight had primary malignant bone tumours. There were eight men and 13 women with a mean age of 54.6 years ( 29 to 81 ). All patients underwent pre-operative staging including plain radiographs, MR imaging, and CT scans.

The prosthesis. The goal in the design of the peri-acetabular replacement prosthesis was an implant which allowed the remaining ilium to support a horizontal acetabular component secured with internal fixation and bone cement. As seen on the AP pelvic radiograph, the remaining part of the ilium lies as an externally-sloping broad curved bony plate. The external surface of the ilium provides a surface to support the prosthesis and offers improved load distribution compared with the window needed for a conventional saddle prosthesis. Accordingly, a wide and sloping metal support wing plate has been designed to conform to the external surface of the ilium. This can provide an area of support for the peri-acetabular replacement prosthesis which exceeds the area available to saddle implants. As the inner table is also accessible at operation, the distal end of the wing plate is produced to curve round the edge of the resected ilium and extend along the inner aspect of the remaining bony plate. In essence the ilium is sandwiched between the two wing-shaped metal plates of the prosthesis. Since these plates are external to the ilium, the periacetabular replacement prosthesis can accommodate greater flexibility in the level of resection. The gap between the plates exceeds $2 \mathrm{~cm}$ to accommodate even the thickest ilium. This clearance allows for the valgus and varus adjustment of the prosthesis in order to create a horizontal acetabular component.

Surgical technique. Distally, the wing plates are joined together where the prosthesis expands into a bell shape. The recess provides a shell which accepts a captive polyethylene liner for articulation with a prosthetic femoral head. A captive liner is required because of the loss of the muscular attachments from the ilium as part of the resection. Using this implant results in proximal placement of the new acetabular articulation which requires accommodation using an ' $\mathrm{L}$-shaped femoral extension which engages on the morse taper of the femoral component. This extends the femoral component and, to the extension piece, a modular femoral head can be applied (Fig. 1). 


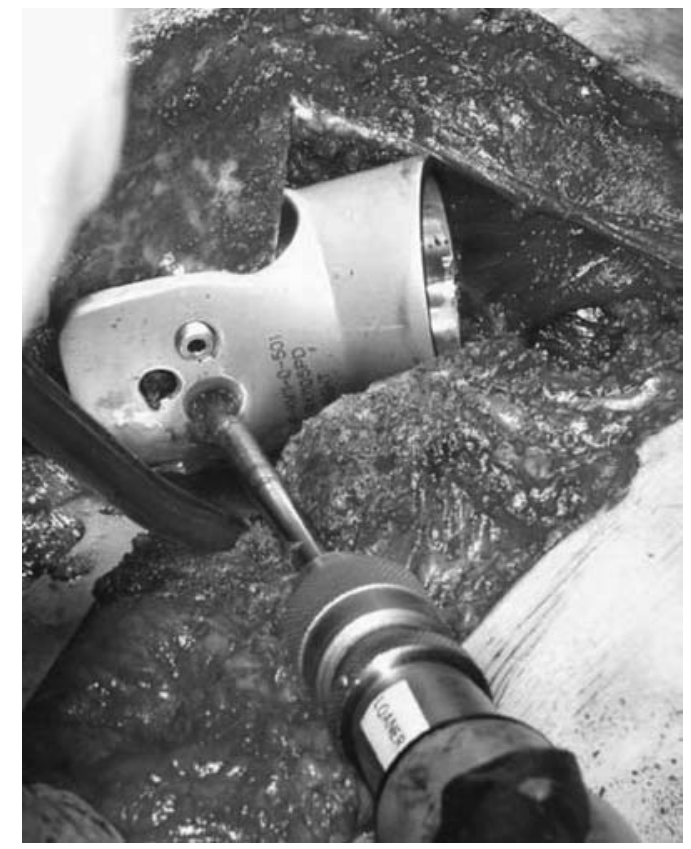

Fig. 2

Intra-operative photograph of the right hip showing the peri-acetabular replacement positioned as far posteriorly as possible on the remaining ilium with holes for three cross-locking bolts drilled from the outer wing of the implant to the inner wing in order to provide stable fixation to the remaining bone.

All operations were performed by the senior author (LRM). A standard iliofemoral approach was used. For patients with metastatic disease, either intralesional or marginal procedures were performed as the goal was palliation and functional reconstruction. For the patients with primary lesions, wide resections were performed as the goal was surgical cure with a functional reconstruction.

After resection of the tumour, the prosthesis is tested and placed as far posteriorly on the iliac wing as possible to decrease the moment arm across the prosthesis to the sacroiliac joint and subsequently reduce shear forces across the joint. Through a template, a semi-circular hole of $0.75 \mathrm{~cm}$ radius is created in the remaining part of the iliac wing using a high speed burr to provide the initial stability of the peri-acetabular prosthesis in the AP plane.

The varus-valgus alignment of the prosthesis is then adjusted and three locking bolts are passed between the wings of the device to secure it to the remaining ilium (Fig. 2). The space posterior to the prosthesis is packed with Gelfoam (Pharmacia \& Upjohn, Kalamazoo, Michigan) to protect the soft tissues from extruded cement which is used to pack the spaces between the wing plates and the ilium anteriorly and posteriorly. After polymerisation of the cement, the femur is prepared in the standard fashion and the femoral component cemented in position. The appropriate femoral extension, neck length of the modular femoral head and trial liner are

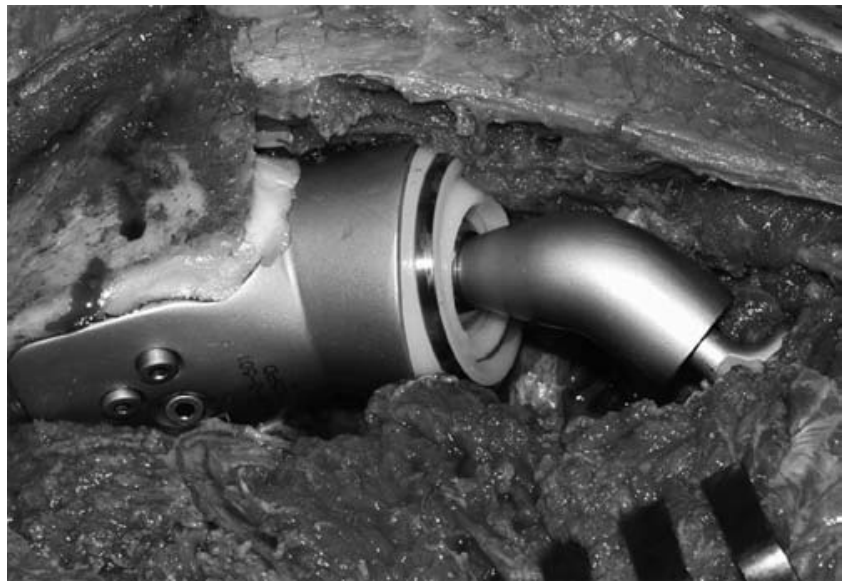

Fig. 3

Intra-operative photograph of the right hip showing the final reconstruction in place with a constrained polyethylene liner and femoral component. Polymethymethacrylate cement has been applied to the spaces between the wing plates and the ilium on both sides for additional fixation.

selected to permit a trial reduction (Fig. 3). This should enable stable flexion of the hip to a minimum of $90^{\circ}$.

Post-operative care. Post-operatively, patients are allowed immediate full weight-bearing as tolerated without use of a protective brace. They were reviewed every three months for the first two years, then every six months between two and five years, and yearly thereafter (Fig. 4).

The medical records were retrospectively reviewed for the complications and causes of failure including infection, tumour recurrence, aseptic loosening, fatigue failure of the prosthesis, peri-prosthetic fracture, and dislocation.

Functional outcome was assessed for all surviving patients using the revised musculoskeletal tumor society (MSTS) functional rating system. ${ }^{16}$ This system uses a 30 -point scale to equally weight each of six parameters, including pain, functional limitation, walking distance, use of support, emotional acceptance, and gait. Patients were interviewed by telephone or at their latest follow-up visit and administered the questionnaire by an investigator (YF) who was not involved in their care.

\section{Results}

At the time of the study, ten patients were alive and 11 had died from their disease (Table I). The mean overall follow-up was 20.5 months (1 to 77). The most common complication was deep infection, which occurred in six patients. All required further surgery, and five underwent revision or removal of the implant; the sixth underwent debridement with retention of the implant. Three patients developed a superficial wound infection, each successfully treated topically with local debridement and oral antibiotics.

Local recurrence of disease occurred in four patients, two of whom underwent further resection and revision of the 


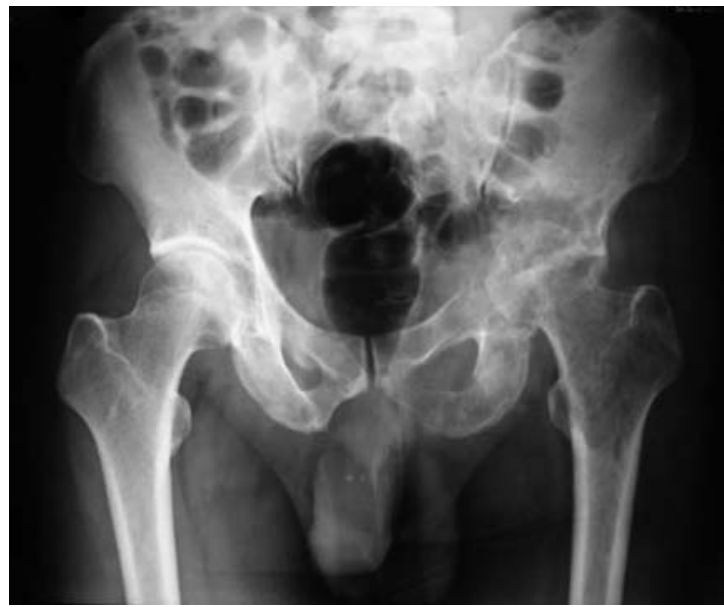

Fig. $4 \mathrm{a}$

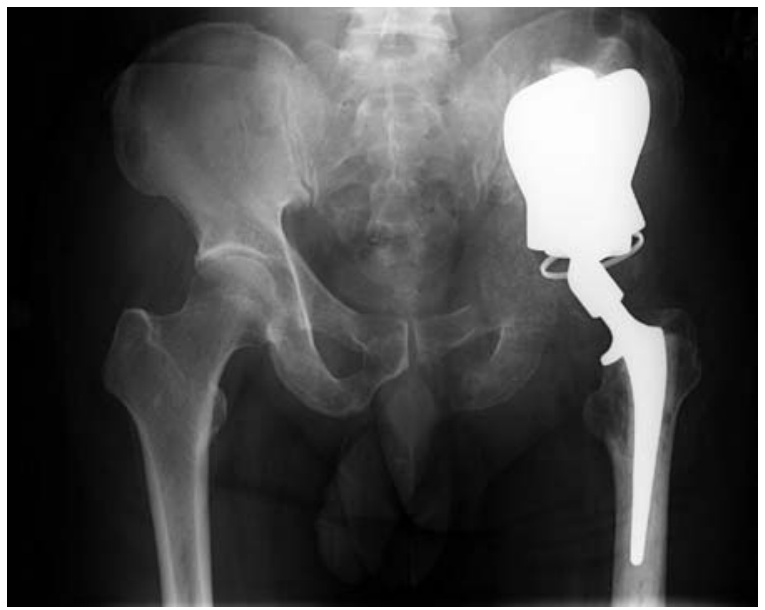

Fig. $4 b$

a) Anteroposterior plain radiograph of the pelvis of a 75-year-old man with a metastatic lung lesion involving the acetabulum showing protrusion of the femoral head because of complete destruction of the medial wall and roof of the acetabulum. b) Post-operative plain radiograph taken at six months showing the reconstruction.

prosthesis because of implant loosening from a pathological fracture of the pelvis. These same two patients had associated deep-infection and later underwent resection, debridement, implant removal, antibiotic spacer placement and subsequent re-implantation for persistent infection.

An intra-operative death occurred in a patient with metastatic disease who died from anaesthesia-related complications.

Two patients had a dislocation following a fall; both required further surgery with exchange of the liner. No attempt at closed reduction was made in either patient because of the obvious nature of the failed liner revealed on radiographs and the anticipated difficulty of closed reduction. In both patients the constraining ring on the liner had broken.

The mean MSTS functional outcome scores of the ten surviving patients was 20.1 (11 to 27 ), of whom nine had the prosthesis in place and one had removal of all implants without re-implantation. The mean emotional acceptance score was 4 (3 to 5 ) and the mean satisfaction score was 4.1 ( 3 to 5 ), the maximum score for both of these criteria is 5 . Canes and walking frames were used by all patients, primarily for balance and weakness; only one patient failed to recover the ability to walk. All patients were able to flex their hip to a minimum of $90^{\circ}$, allowing for comfortable sitting. Weakness in hip abductor and flexor strength accounted for the majority of the functional deficit. All patients had a pronounced Trendelenburg gait. ${ }^{17}$ The mean time to return to walking was three weeks (2 to 4 ).

\section{Discussion}

To date, the Mark II saddle prosthesis has been the only modular system available for acetabular reconstruction fol- lowing type II resection. ${ }^{10-15}$ Several studies have shown good results in small series when using this prosthesis. In a series of 17 patients, ten had an excellent, two a good, one a fair and four a poor outcome, ${ }^{10}$ with an overall complication rate of $53 \%$ which included two dislocations and two prosthetic dissociations. It was concluded that the saddle could be used with favourable results and suggested that further modifications may help minimise the mechanical problems. A series reporting a variety of techniques for pelvic reconstruction in 39 patients, of whom 29 underwent replacement with a polyacetal resin replacement, eight with a custom-made vitallium prosthesis, and two with a saddle prosthesis, ${ }^{18} 13$ of the 19 surviving patients had a good or excellent result and six had a dislocation. Another study of 15 patients treated with pelvic replacement concluded that internal hemipelvectomy combined with endoprosthetic replacement was the treatment of choice for acetabular lesions, provided that a complete resection was feasible. ${ }^{19}$

Our series presents the results of a novel peri-acetabular replacement prosthesis, in a mixed series of patients 13 with metastases and eight with primary tumours. The mean MSTS score of the patients in our study was 20.1, which is higher than the 15.3 to 16.6 reported in literature. ${ }^{11,20}$

The overall incidence of complications in our study was $66 \%$ (14 of 21 patients) and is similar to the $53 \%$ to $65 \%$ reported in other studies. ${ }^{10,12}$ The high rate of complications can be attributed to patients' poor overall health, the presence of metastatic disease, and concurrent chemotherapy/radiotherapy. The most common complication was infection, which required implant revision in five patients which is also similar to the findings of other studies which reported deep infection rates ranging between $22 \%$ and $39 \% .^{11,14,15}$ Based on our experience, we feel it is cru- 
Table I. Demographic information for the 21 patients undergoing reconstruction with the peri-acetabular reconstruction prosthesis

\begin{tabular}{|c|c|c|c|c|c|c|c|c|}
\hline Case & $\begin{array}{l}\text { Age } \\
\text { (yrs) }\end{array}$ & $\begin{array}{l}\text { Gen- } \\
\text { der }\end{array}$ & $\begin{array}{l}\text { Diagnosis*/Enneking } \\
\text { stage }^{21}\end{array}$ & $\begin{array}{l}\text { Resection } \\
\text { margin }\end{array}$ & $\begin{array}{l}\text { Adjuvant ther- } \\
\text { apy }^{\dagger}\end{array}$ & $\begin{array}{l}\text { Follow-up } \\
\text { (mths) }\end{array}$ & $\begin{array}{l}\text { MSTS } \\
\text { score }^{16}\end{array}$ & Complications \\
\hline 1 & 29 & $\mathrm{M}$ & OGS/IIB & Wide & PrC, PoC & 34 , alive & 22 & Wound infection \\
\hline 2 & 56 & $\mathrm{~F}$ & $\mathrm{CS} / \mathrm{IIB}$ & Wide & None & 20, deceased & NA & None \\
\hline 3 & 62 & $\mathrm{~F}$ & $\mathrm{CS} / \mathrm{IIB}$ & Wide & None & 20, deceased & NA & None \\
\hline 4 & 35 & $\mathrm{~F}$ & $\mathrm{CS} / \mathrm{IIB}$ & Wide & PoC, PoR & 21 , alive & 24 & None \\
\hline 5 & 46 & $\mathrm{~F}$ & $\mathrm{CS} / \mathrm{IIB}$ & Wide & None & 14 , alive & 23 & Tumour recurrence \\
\hline 6 & 67 & $\mathrm{M}$ & $\mathrm{CS} / \mathrm{IIB}$ & Wide & None & 40, deceased & NA & None \\
\hline 7 & 36 & $\mathrm{~F}$ & $\mathrm{CS} / \mathrm{IIB}$ & Wide & PoC, PoR & 36, alive & 24 & $\begin{array}{l}\text { Tumour recurrence, } \\
\text { deep infection, } \\
\text { revision, }\end{array}$ \\
\hline 8 & 32 & $\mathrm{M}$ & Ewings sarcoma/IIB & Wide & PrC, PoC, PrR & 40 , alive & 23 & None \\
\hline 9 & 81 & $\mathrm{M}$ & Metastatic renal cancer/NA & Marginal & PrC, PoC, PoR & 1, deceased & NA & Wound infection \\
\hline 10 & 48 & $\mathrm{~F}$ & Metastatic renal cancer & Marginal & PrC, PoC, PoR & 8, alive & 17 & None \\
\hline 11 & 77 & $\mathrm{M}$ & Metastatic renal cancer/NA & Marginal & PrC, PoC, PoR & NA & NA & $\begin{array}{l}\text { Intra-operative } \\
\text { mortality }\end{array}$ \\
\hline 12 & 42 & $\mathrm{~F}$ & Metastatic renal cancer/NA & Marginal & PrC, PoC, PoR & 3, deceased & NA & Tumour recurrence \\
\hline 13 & 58 & $\mathrm{~F}$ & Metastatic renal cancer/NA & Marginal & PrC, PoC, PoR & 18, deceased & NA & $\begin{array}{l}\text { Dislocation, } \\
\text { revision }\end{array}$ \\
\hline 14 & 46 & $\mathrm{~F}$ & Metastatic breast cancer/NA & Marginal & PrC, PoC, PoR & 19, deceased & NA & Deep infection \\
\hline 15 & 56 & $\mathrm{~F}$ & Metastatic breast cancer/NA & Marginal & PrC, PoC, PoR & 12, deceased & NA & Wound infection \\
\hline 16 & 74 & $\mathrm{~F}$ & Metastatic breast cancer/NA & Marginal & PrC, PoC, PoR & 9, deceased & NA & $\begin{array}{l}\text { Deep infection, } \\
\text { revision }\end{array}$ \\
\hline 17 & 75 & $\mathrm{M}$ & Metastatic lung cancer/NA & Intralesional & PrC, PoC, PoR & 10, deceased & NA & $\begin{array}{l}\text { Deep infection, } \\
\text { revision }\end{array}$ \\
\hline 18 & 71 & $\mathrm{~F}$ & Metastatic ovarian cancer/NA & Marginal & PrC, PoC, PoR & 9 , alive & 11 & None \\
\hline 19 & 49 & M & Metastatic bladder cancer/NA & Intralesional & PrC, PoC, PoR & 15 , alive & 14 & $\begin{array}{l}\text { Dislocation, } \\
\text { revision }\end{array}$ \\
\hline 20 & 53 & $\mathrm{M}$ & Metastatic thyroid cancer/NA & Marginal & PrC, PoR & 77 , alive & 27 & $\begin{array}{l}\text { Tumour recurrence, } \\
\text { deep infection, } \\
\text { revision }\end{array}$ \\
\hline 21 & 54 & $\mathrm{~F}$ & Metastatic cervical cancer/NA & Marginal & PrC, PoC, PrR & 4 , alive & 16 & $\begin{array}{l}\text { Deep infection, } \\
\text { removal of all } \\
\text { implants }\end{array}$ \\
\hline
\end{tabular}

* OGS, osteogenic sarcoma; CS, chondrosarcoma; NA, not applicable

† PrC, pre-operative chemotherapy; PoC, post-operative chemotherapy; PoR, post-operative radiation; PrR, pre-operative radiation ‡ MSTS, musculoskeletal tumour society; NA, not applicable

cial to have an adequate soft-tissue envelope for the implant. The resection may lead to poor vascularity of the overlying soft-tissue flaps and increase the risk of local infection. In selected cases, where we anticipate extensive resection and poor local cover, we now consult a plastic surgeon pre-operatively in order to plan for a possible reconstructive procedure.

Implant-related complications with the Mark II saddle prosthesis have been reported to range between $22 \%$ and $53 \% .{ }^{11-13}$ Common problems include progressive erosion and superior migration of the saddle, often leading to sciatic nerve palsy and a flail leg. ${ }^{11-13}$ Additional problems have included dislocation of the saddle from the ilium and dissociation of the saddle prosthesis from the femoral component. ${ }^{11-13}$ Our implant-related complications were limited to two dislocations of the femoral component from the peri-acetabular replacement after falls. However, none of the patients had failure at the ilium-saddle interface, which was the site of most dislocations in earlier studies. ${ }^{11-13}$ The design of this novel peri-acetabular replacement prosthesis provides greater inherent stability. The fixation to the remaining ilium prevents erosion of the bone and migration of the implant.
Based on our experience, we recommend the continued use of this prosthesis for use in large pelvic defects after type II pelvic resection.

No benefits in any form have been received or will be received from a commercial party related directly or indirectly to the subject of this article.

\section{References}

1. Frassica FJ, Sim FH. Pathogenesis and prognosis. In: Sim FH, ed. Diagnosis and management of metastatic bone disease: a multidisciplinary approach. New York: Raven Press, 1988:1-6.

2. Enneking WF, Dunham WK. Resection and reconstruction for primary neoplasms involving the innominate bone. J Bone Joint Surg [Am] 1978;60-A:731-46.

3. Fuchs B, O'Connor MI, Kaufman KR, Padgett DJ, Sim FH. lliofemoral arthrodesis and pseudarthrosis: a long-term functional outcome evaluation. Clin Orthop 2002;397:29-35.

4. O'Connor MI. Malignant pelvic tumors: limb-sparing resection and reconstruction. Semin Surg Oncol 1997;13:49-54.

5. O'Connor MI, Sim FH. Salvage of the limb in the treatment of malignant pelvic tumors. J Bone Joint Surg [Am]1989;71-A:481-94.

6. Beadel GP, McLaughlin CE, Wunder JS, et al. Outcome in two groups of patients with allograft-prosthetic reconstruction of pelvic tumor defects. Clin Orthop 2005;438:30-5.

7. Bell RS, Davis AM, Wunder JS, et al. Allograft reconstruction of the acetabulum after resection of stage-IIB sarcoma: intermediate-term results. J Bone Joint Surg [Am] 1997;79-A:1663-74.

8. Delloye C, Banse X, Brochard B, Docquier PL, Cornu O. Pelvic reconstruction with a structural pelvic allograft after resection of a malignant bone tumor. $J$ Bone Joint Surg [Am]2007;89-A:579-87. 
9. Windhager R, Karner J, Kutschera HP, et al. Limb salvage in periacetabular sarcomas: review of 21 consecutive cases. Clin Orthop 1996;331:265-76.

10. Aboulafia AJ, Buch R, Mathews J, Malawer MM. Reconstruction using the saddle prosthesis following excision of primary and metastatic periacetabular tumors. Clin Orthop 1995;314:203-13.

11. Aljassir F, beadel GP, Turcotte RE, et al. Outcome after pelvic sarcoma resection reconstructed with saddle prosthesis. Clin Orthop 2005;438:36-41.

12. Cottias $\mathbf{P}$, Jeanrot C, Vinh TS, Tomeno B, Anract P. Complications and functional evaluation of 17 saddle prostheses for resection of periacetabular tumors. J Surg Onc 2001;78:90-100

13. Kitagawa Y, Ek ET, Choong PF. Pelvic reconstruction using saddle prosthesis following limb salvage operation for periacetabular tumour. J Orthop Surg (Hong Kong) 2006;14:155-62.

14. Renard AJ, Veth RP, Schreuder HW, et al. The saddle prosthesis in pelvic primary and secondary musculoskeletal tumors: functional results at several postoperative intervals. Arch Orthop Trauma Surg 2000;120:188-94.
15. Nieder E, Elson RA, Engelbrecht E, et al. The saddle prosthesis for salvage of the destroyed acetabulum. J Bone Joint Surg [Br] 1990;72-B:1014-22.

16. Enneking WF, Dunham W, Gebhardt MC, Malawar M, Pritchard DJ. A system for the functional evaluation of reconstructive procedures after surgical treatment of tumors of the musculoskeletal system. Clin Orthop 1993;286:241-6.

17. Trendelenburg F. Trendelenburg's test: 1895. Clin Orthop 1998;355:3-7.

18. Wirbel RJ, Schulte M, Maier B, Mutschler WE. Megaprosthetic replacement of the pelvis: function in 17 cases. Acta Orthop Scand 1999;70:348-52.

19. Bruns J, Luessenhop SL, Dahmen G Sr. Internal hemipelvectomy and endoprosthetic pelvic replacement: long-term follow-up results. Arch Orthop Trauma Surg 1997;116:27-31.

20. Benevenia J, Cyran FP, Biermann JS, Patterson FR, Leeson MC. Treatment of advanced metastatic lesions of the acetabulum using the saddle prosthesis. Clin Orthop 2004;426:23-31.

21. Enneking WF, Spanier SS, Goodman MA. A system for the surgical staging of musculoskeletal sarcoma. Clin Orthop 1980;153:106-20. 